\title{
In Memory of Eduard Zinov'evich Lyubimskii
}

\author{
November 25, 1931-February 13, 2008
}

DOI: $10.1134 / \mathrm{S} 0361768809010010$

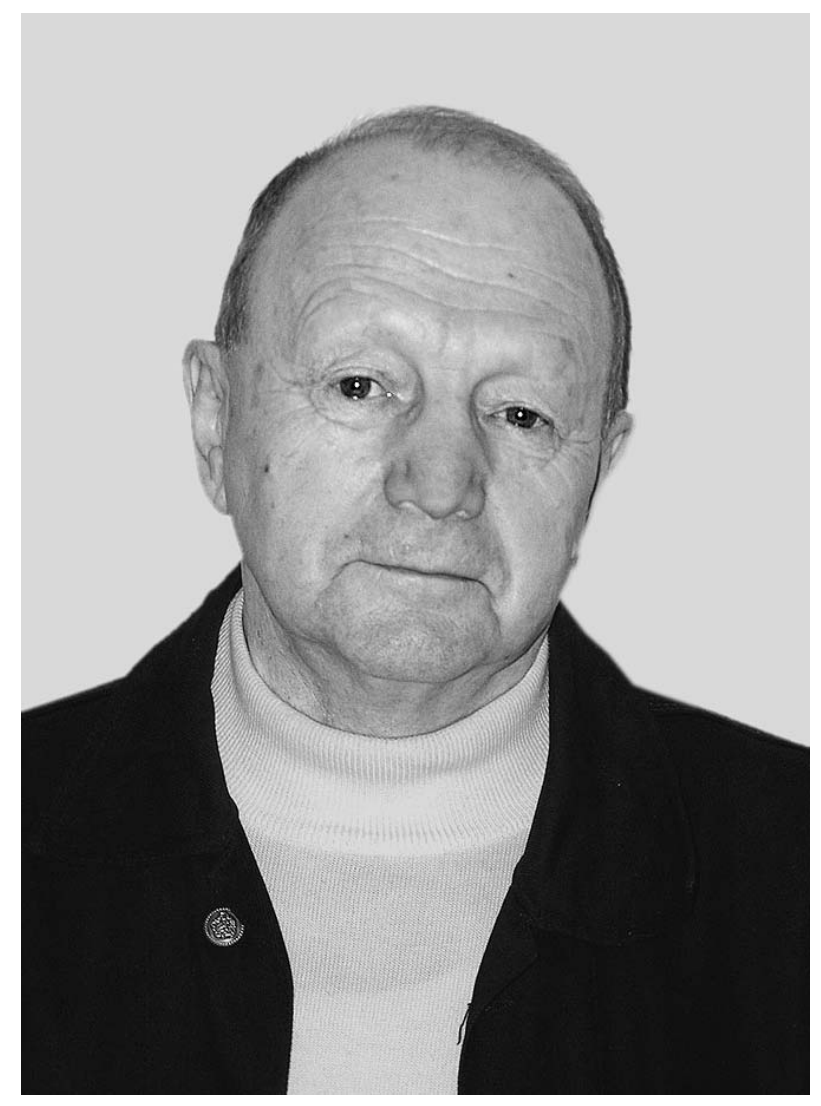

It has been a year since Prof. Eduard Zinov'evich Lyubimskii passed away. He was a bright representative of the honored generation of the first domestic programmers, who bore on their shoulders all the difficulties of building the science of programming in our country.

For all of us who were closely acquainted with Eduard Zinov'evich, for his colleagues and students, the company of this charming and interesting man was a bright page of life to keep in our memories forever.

Lyubimskii's professional activity encompassed seemingly rather incompatible matters. He was a highly skilled programmer who wrote programs for the first Soviet computers. He was a universal programmer who passed by all the milestones of the development of programming, starting from creation of the first Soviet program generator in 1954, the first Soviet compiler from the full version of Algol in 1963, and programming systems (ALMO) to the development of operating systems (OS IPM) and realization of large-scale projects. A number of studies headed by Lyubimskii on nonprocedural programming languages and planning of purposeful activity are well known in the field of artificial intelligence.

Having as he did a special talent, or even intuition, Eduard Zinov'evich put forward the ideas of constructing systems of programs that interact on the same principles as groups of people (postal, emergency, and other processes in operating systems) as early as in the period of development of the operating system OS IPM for the BESM-6. Later, these ideas were partly presented in the paper "Using Ideas of a Collective in Complex Programming System Structures" written along with S.S. Kamynin.

During his last years, Eduard Zinov'evich achieved successes in the development of software for grid infrastructures. In his presentations, he repeatedly put forward the idea of the necessity of development of a special jurisdiction and a system of rules of ethics in a community of programs to avoid self-organization of artificial intelligence, which may lead to unpredictable consequences. In his paper published in this issue of the journal, this idea (as are all the ideas of Eduard Zinov'evich) is expressed in a crystal-clear and understandable form. This paper can now be viewed as Lyubimskii's last testament. 